19 Revue d'histoire du XIXe siècle

Société d'histoire de la révolution de 1848 et des

révolutions du XIXe siècle

$24 \mid 2002$

Varia

\title{
Nicole MOZET et Paule PETITIER [dir.], Balzac dans
}

l'Histoire

"Collection du Bicentenaire", Paris, Éditions SEDES, 2001, 284 p.

Boris Lyon-Caen

\section{(2) OpenEdition}

Journals

Édition électronique

URL : http://journals.openedition.org/rh19/391

DOI : 10.4000/rh19.391

ISSN : $1777-5329$

Éditeur

La Société de 1848

Édition imprimée

Date de publication : 1 juin 2002

Pagination : 194-195

ISSN : 1265-1354

Référence électronique

Boris Lyon-Caen, « Nicole MOZET et Paule PETITIER [dir.], Balzac dans l'Histoire », Revue d'histoire du XIXe siècle [En ligne], 24 | 2002, mis en ligne le 04 juin 2003, consulté le 22 septembre 2020. URL http://journals.openedition.org/rh19/391 ; DOI : https://doi.org/10.4000/rh19.391

Ce document a été généré automatiquement le 22 septembre 2020

Tous droits réservés 


\title{
Nicole MOZET et Paule PETITIER [dir.], Balzac dans l'Histoire
}

\author{
"Collection du Bicentenaire", Paris, Éditions SEDES, 2001, 284 p.
}

\section{Boris Lyon-Caen}

Le titre de ce volume, fruit du "colloque du Bicentenaire" organisé à Tours en octobre 1999, peut prêter à confusion. Balzac dans l'Histoire explore en effet, après les travaux fondateurs de Louis Chevalier, de Georg Lukács et de Pierre Barbéris, le statut de l'Histoire dans Balzac : ses modes d'apparition dans le texte balzacien, c'est-à-dire à la fois son inscription et sa construction. Plus précisément, l'auteur de La Comédie humaine y apparaît comme l'inventeur d'un nouveau régime du savoir. De l'histoire pratiquée jusqu'à lui, Balzac renouvelle à la fois les objets, la pratique et les finalités. Les objets, puisqu'il se fait à partir de 1830 l'observateur attentif du temps présent --de "cette histoire oubliée par tant d'historiens, celle des mœurs" (Avant-propos de La Comédie humaine). La pratique, puisqu'il transforme les complexités de la vie privée en principes de composition romanesque, accordant une large place aux aléas des causalités incongrues et aux hasards les plus imprévus. Les finalités, enfin, puisqu'il ne ressort de sa société fictive ni reconstitution fidèle (qualifiée de "réaliste" par l'histoire littéraire traditionnelle) ni philosophie de l'histoire (focalisée exclusivement sur 1789 ou 1830); à égale distance de ces deux polarités, la littérature selon Balzac a pour fonction, comme le rappelle la préface d'Une fille d'Ève, de "fabriquer le temps".

Balzac dans l'Histoire est constitué de trois parties relativement homogènes. Dans la première partie, "Croisements", littéraires et historiens examinent comment se sont identifiées et différenciées dans le discours balzacien les pratiques discursives du premier XIXe siècle ; pour ce faire, ils analysent le rapport qu'entretient La Comédie humaine avec les sciences sociales, le modèle juridique, les "tableaux de Paris", le genre consulaire et impérial des "Mémoires" ou l'autobiographie. La deuxième partie, "Représentations", explore les scénographies de l'histoire qui sont à l'œuvre dans le texte balzacien, et tout particulièrement l'écriture de la violence (de l'insurrection, de la chouannerie, du pouvoir absolu) qui en procède ; au terme d'un exercice exemplaire de critique littéraire, Franc Schuerewegen affirme ici que l'écrivain "a le pouvoir de dire l'Histoire autrement, risquons ici l'adverbe : érotiquement. L'écrivain est l'homme 
qui sait rendre l'Histoire excitante, c'est son originalité, c'est sa force". Enfin, la troisième partie, intitulée "L'auteur-siècle", nous permet d'étudier comment s'est pensée l'histoire avec Balzac : Éric Bordas, par exemple, met en évidence la "nouvelle mesure du rapport au temps" qu'instituent Les Contes drolatiques, cet autre de La Comédie humaine, cette "expérimentation de l'espace littéraire non assujettie au terrorisme de la transitivité référentielle" et exprimant "l'ordre d'un temps possible à ce moment de l'histoire" ; Jacques Neefs, lui, met en lumière les différentes modalités du "passage de l'histoire" dans la fiction balzacienne, parmi lesquelles les idées d'irréversibilité et de réconciliation ont une importance cruciale ; José-Luis Diaz examine dans quelle mesure le XIX siècle est moins pour Balzac l'objet d'un enregistrement passif que d'une prise de possession, d'une appropriation active ; Jean-Claude Caron, enfin, recense et analyse les usages de l'œuvre balzacienne dans la production historique du dernier demi-siècle. Assurément, ce volume touffu est d'importance. Il contribue d'abord au renouveau des études balzaciennes ; et ce, en expliquant comment "le désenchantement qui congédie la grande Histoire ouvre au romancier l'exploration mélancolique de la comédie humaine, la lucidité du réalisme critique" (Paule Petitier). D'autre part, loin désormais de toute théorie du reflet, il regroupe un certain nombre de pistes de réflexion non négligeables pour notre compréhension du premier XIX ${ }^{\mathrm{e}}$ siècle et du rôle qu'y a joué la production romanesque. Enfin, comme pour satisfaire aux attentes conjointes du lecteur "littéraire" et du lecteur "historien", l'apport majeur de Balzac dans l'Histoire est d'engager ou de réengager l'histoire littéraire sur les voies de l'interdisciplinarité ; façon de conférer au principe même de colloque des vertus pacificatrices et de prouver le mouvement, une fois n'est pas coutume, en marchant. 